\title{
Poultry as a Host for the Zoonotic Pathogen Campylobacter jejuni
}

\author{
David Hermans, ${ }^{1}$ Frank Pasmans, ${ }^{1}$ Winy Messens, ${ }^{2, *}$ An Martel, ${ }^{1}$ Filip Van Immerseel, \\ Geertrui Rasschaert, ${ }^{2}$ Marc Heyndrickx, ${ }^{1,2}$ Kim Van Deun, and Freddy Haesebrouck ${ }^{1}$
}

\begin{abstract}
Campylobacteriosis is the most reported foodborne gastroenteritic disease and poses a serious health burden in industrialized countries. Disease in humans is mainly caused by the zoonotic pathogen Campylobacter jejuni. Due to its wide-spread occurrence in the environment, the epidemiology of Campylobacter remains poorly understood. It is generally accepted, however, that chickens are a natural host for Campylobacter jejuni, and for Campylobacter spp. in general, and that colonized broiler chicks are the primary vector for transmitting this pathogen to humans. Several potential sources and vectors for transmitting C. jejuni to broiler flocks have been identified. Initially, one or a few broilers can become colonized at an age of $>2$ weeks until the end of rearing, after which the infection will rapidly spread throughout the entire flock. Such a flock is generally colonized until slaughter and infected birds carry a very high C. jejuni load in their gastrointestinal tract, especially the ceca. This eventually results in contaminated carcasses during processing, which can transmit this pathogen to humans. Recent genetic typing studies showed that chicken isolates can frequently be linked to human clinical cases of Campylobacter enteritis. However, despite the increasing evidence that the chicken reservoir is the number one risk factor for disease in humans, no effective strategy exists to reduce Campylobachter prevalence in poultry flocks, which can in part be explained by the incomplete understanding of the epidemiology of $C$. jejuni in broiler flocks. As a result, the number of human campylobacteriosis cases associated with the chicken vector remains strikingly high.
\end{abstract}

Key Words: Campylobacteriosis-Campylobacter jejuni-Chicken vector-Zoonosis.

\section{Introduction}

C AMPYLOBACTER INFECTIONS ARE NOW the leading cause of human bacterial gastroenteritis in many developed countries. Although the number of registered campylobacteriosis cases has declined slightly in some parts of the world during recent years, the overall disease burden is still noteworthy (Ailes et al. 2008, EFSA and ECDC 2011). The true incidence of campylobacteriosis in industrialized countries is uncertain since many unreported infections occur for every diagnosed case. In the United States, the Foodborne Diseases Active Surveillance Network (FoodNet) reported an incidence of culture-confirmed Campylobacter infections in the FoodNet sites of 12.7 per 100,000 persons in 2006 (Ailes et al. 2008). These numbers represent a $30 \%$ decline compared to the 1996 situation, but the incidence still remains above the national health objective. Most other regions of the world report a higher disease incidence, with strikingly high numbers in New Zealand in 2003 of almost 400 cases per 100,000 people (Baker et al. 2007). Within the European Union campylobacteriosis has been the most frequently reported zoonotic disease in humans as from 2004. In 2009, the overall EU notification rate was 45.6 cases per 100,000 inhabitants (EFSA and ECDC 2011). Campylobacter enteritis in humans is mainly caused by Campylobacter jejuni (EFSA and ECDC 2011). In 2009, C. jejuni accounted for $90 \%$ of the cases characterized at species level. Campylobacter coli, Campylobacter lari, and Campylobacter upsaliensis accounted only for, respectively, $2.5 \%, 0.2 \%$, and $0.01 \%$ of the isolates. The remainder of the speciated isolates included other (unknown) species. Regional

\footnotetext{
${ }^{1}$ Department of Pathology, Bacteriology and Avian Diseases, Faculty of Veterinary Medicine, Ghent University, Merelbeke, Belgium.

${ }^{2}$ Institute for Agricultural and Fisheries Research, Technology and Food Unit, Melle, Belgium.

*At the time of the finalization of this article: Institute for Agricultural and Fisheries Research, Technology and Food Unit, Melle, Belgium; Current affiliation: Senior Scientific Officer, Biological Hazards (BIOHAZ) Unit, European Food Safety Authority (EFSA), Parma, Italy.
} 
or country differences, however, do exist: in Bosnia and Herzegovina, for instance, a higher prevalence of C. coli in sporadic human infections $(30 \%)$ has been noted (UzunovićKamberović et al. 2007).

As will be further on discussed in this review, there is increasing evidence that poultry is the number one contributor to disease in humans. Nevertheless, no effective strategy exists to clear Campylobacter from broiler flocks (Hermans et al. 2011a). Although some reduction in the number of colonized flocks was observed upon implementing specific hygienic control strategies, as well as in bacterial counts from colonized birds upon therapeutic feeding with anti-Campylobacter substances, no commercial product is available that effectively prevents or reduces Campylobacter colonization of the avian gut. Therefore, the number of human campylobacteriosis cases remains strikingly high. In the next sections, the prevalence of Campylobacter in the environment and animal hosts will be discussed and poultry animals will be identified as a natural host for this zoonotic pathogen. These birds are under a constant contamination pressure and lots of risk factors can contribute to Campylobacter colonization in poultry, being in part responsible for the failure of current control measures. A thorough discussion of these risk factors will finally be followed by highlighting the poultry reservoir as the main contributor to campylobacteriosis in humans.

\section{Campylobacter Prevalence in Animals and the Environment}

Paradoxally, despite its fastidious, fragile nature, Campylobacter is highly prevalent in the environment and can survive for prolonged periods both inside and outside a suitable host (Newell 2002, Murphy et al. 2006). How the microorganism copes with stresses encountered in the environment still remains enigmatic, but, clearly, Campylobacter developed some survival mechanisms to overcome these stressors (Murphy et al. 2006). The presence of highly mutable sites in the C. jejuni genome is responsible for its rapid adaptation in a novel host (Jerome et al. 2011). Campylobacter can be frequently found in surface water and is part of the natural intestinal microbiota of a wide range of wild and domestic animals, especially poultry (Newell 2002, Whyte et al. 2004, Abulreesh et al. 2006, Young et al. 2007, Ogden et al. 2009, Jokinen et al. 2011). The estimated Campylobacter prevalence in poultry and nonpoultry farm animals depends on season, age of animal, flock or herd size and type, diet, husbandry practices, and geography, with $C$. jejuni being the most isolated species (Kuana et al. 2008, McDowell et al. 2008, Zweifel et al. 2008, Ellis-Iversen et al. 2009, Messens et al. 2009, Näther et al. 2009, EFSA 2010a, EFSA and ECDC 2011, Jorgensen et al. 2011). In pigs C. coli, however, dominates ( $84 \%$ of the isolates in 2009) (EFSA and ECDC 2011). Surprisingly, in some countries, like Spain, Luxembourg, Slovenia, and Bosnia and Herzegovina, a much higher proportion of $C$. coli compared to C. jejuni was also isolated from poultry samples (Zorman et al. 2006, EFSA and ECDC 2011), which is clearly, at least in part, responsible for the higher prevalence of $C$. coli in sporadic human infections in these latter two countries (see above).

\section{Poultry as a Natural Host for Zoonotic Campylobacter}

Chickens are a natural host for thermotolerant or thermophilic Campylobacter species (containing the above-mentioned species and for simplicity hereafter referred to as Campylobacter) (EFSA and ECDC 2011). The probability of a flock to become colonized increases during rearing, resulting in on average $60 \%-80 \%$ of the analyzed broiler flocks to be positive for Campylobacter species in general at slaughter age worldwide (Herman et al. 2003, Rasschaert et al. 2006, Kuana et al. 2008, Reich et al. 2008, EFSA 2010a). Striking differences in EU prevalence do exist. In 2008, almost all broiler batches in some Northern European countries, like Estonia, Norway, and Finland, were free of Campylobacter, whereas a strikingly high prevalence of $100 \%$ was reported for Luxebmbourg. In general, C. jejuni was found to be the dominating species. Of the analyzed flocks on average $41 \%$ were colonized specifically with C. jejuni in the EU and even up to $55 \%$ in Brazil. Colonized poultry flocks might contaminate the surrounding environment by which Campylobacter is able to spread further and contaminate other farms or humans (Jonsson et al. 2010).

\section{Colonization of Broiler Chickens by C. jejuni at the Farm}

From day-of-hatch until the broiler chickens are transported to the abattoir, the animals can encounter several risk factors contributing to their colonization with C. jejuni. As a consequence, the Campylobacter ecology and epidemiology in broiler flocks is quite complex. An overview of the risk factors involved in the environmental transmission of Campylobacter to broiler flocks is given in Table 1.

\section{Initial broiler flock colonization and colonization pattern}

The cecum is the predominant site for colonization, where the organism resides principally in the mucus layer of cecal crypts (Beery et al. 1988, Meade et al. 2009). C. jejunicolonized broiler chickens carry high bacterial numbers in their ceca (generally around $10^{6}$ to $10^{8} \mathrm{cfu} / \mathrm{g}$ ) and remain colonized until slaughter (Evans 1992, Jacobs-Reitsma et al. 1995, Evans and Sayers 2000, Allen et al. 2008, Stern 2008). Bacterial numbers of up to $10^{12} \mathrm{cfu} / \mathrm{g}$ have been isolated from chicken ceca after oral challenge with $C$. jejuni (Meade et al. 2009). Upon colonization with Campylobacter, the chick immune system is only activated inefficiently and expression of several antimicrobial peptide genes is reduced, which both contribute to the persistent high-level commensal colonization of Campylobacter in the avian gut (Meade et al. 2009, Hermans et al. 2011b).

Initial colonization of broiler chickens probably occurs through horizontal transmission from the environment, whereas vertical transmission from breeder hens or carryover of infection from a positive flock to a new flock in the same house, after cleansing and disinfection, are considered to be unlikely (van de Giessen et al. 1992, Jacobs-Reitsma et al. 1995, Bull et al. 2006, Patriarchi et al. 2011). Indeed, carryover of C. jejuni subtypes between broiler flocks in the same house seems to occur only rarely (Barrios et al. 2006, Colles et al. 2008, McDowell et al. 2008). Persistent clones in the outside environment can, however, be responsible for repeated infection of multiple broiler flock rotations (Petersen and Wedderkopp 2001, Wedderkopp et al. 2003). Some C. jejuni strains can be very persistent in a confined geographical area. In a Lithuanian study, a single amplified fragment length polymorphism type was found in several broiler farms over a 1-year period (Kudirkiene et al. 2010).

Colonization of broiler chickens with C. jejuni is influenced by many factors, including source of the microorganism, the 
Table 1. Risk Factors for Campylobacter Colonization of Broiler Flocks at the Farm

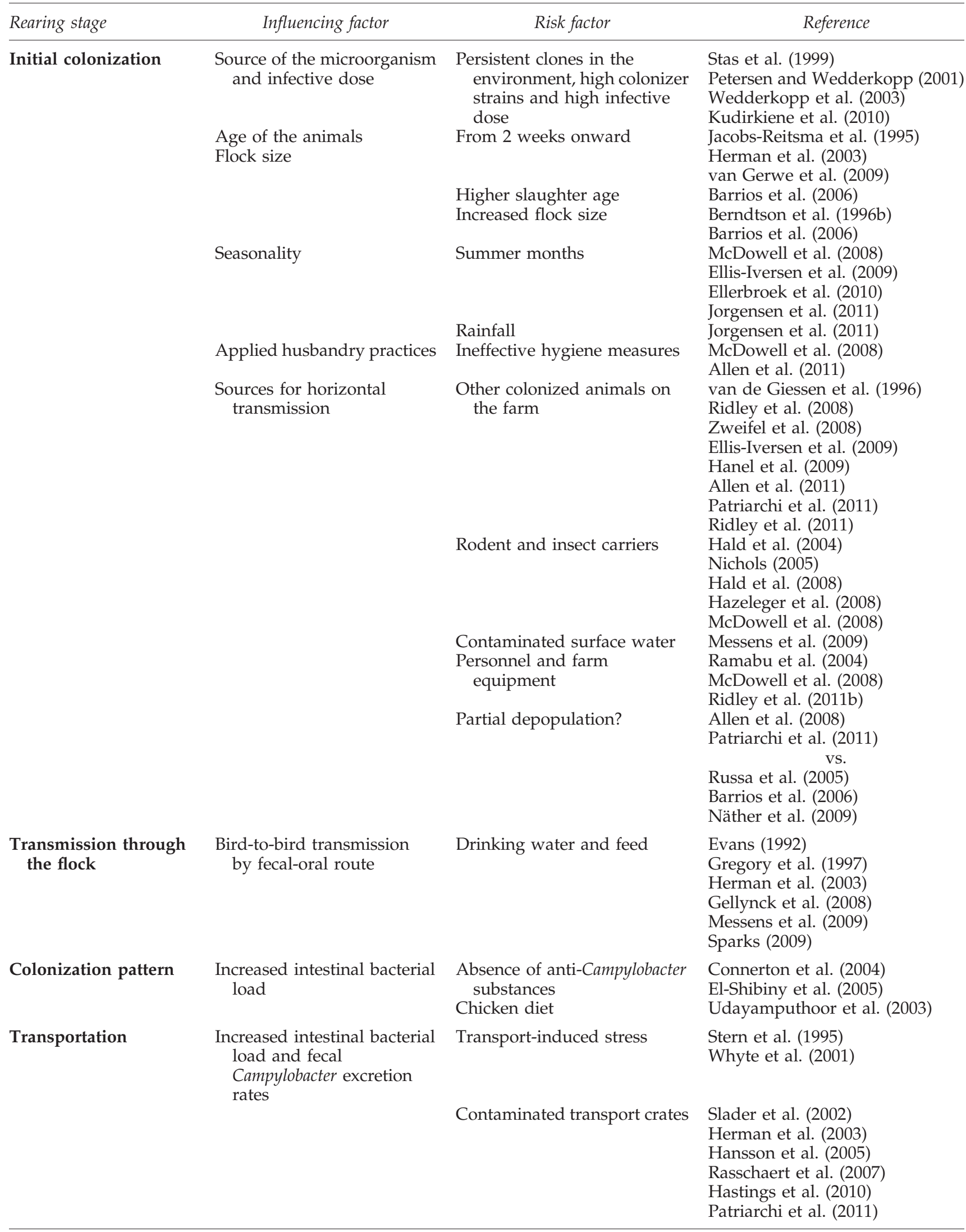


infecting dose, and age of the animal (Stas et al. 1999). Most flocks become colonized only at an age of 2-4 weeks (JacobsReitsma et al. 1995, Berndtson et al. 1996a, Herman et al. 2003, van Gerwe et al. 2009). Protection of young chickens against colonization can be attributed to Campylobacter-specific maternal antibodies (Sahin et al. 2003), the titer of which generally drops after 2 weeks (Cawthraw et al. 1994). As a consequence, after this protection period animals are more susceptible to colonization with Campylobacter and this susceptibility increases with higher slaughter age (Berndtson et al. 1996b, Barrios et al. 2006). Although during colonization antibodies specifically directed against Campylobacter are induced (Cawthraw et al. 1994), the bacterium is apparently not expelled from its host. Also, the time of year clearly has an influence. In Germany and the United Kingom, the risk for broilers to become colonized with Campylobacter is highest during the summer months (McDowell et al. 2008, EllisIversen et al. 2009, Ellerbroek et al. 2010, Jorgensen et al. 2011) and a coincident seasonality of infections in chickens and humans has been shown (Meldrum et al. 2005). In the EUwide baseline survey on Campylobacter in broiler batches in 2008, batches were most likely to be found Campylobacter colonized in the third quarter (July-September) of the year (EFSA 2010b). Very recently, a significant relationship was observed between several climatic factors (such as environmental temperature and amount of sunshine and rainfall) and Campylobacter prevalence in United Kingdom broiler flocks before first partial or full depopulation (Jorgensen et al. 2011), which could explain this observed seasonality. Seasonality/ temperature, however, explained only half of the Campylobacter prevalence, indicating that also other factors such as husbandry practices and biosecurity may also be important. Indeed, a recent study by Allen et al. (2011) in the United Kingdom showed that the colonization of organic flocks is largely dependent on the husbandry practices used on the farm. In contrast, the length of the rearing period did not seem to have a large influence on Campylobacter prevalence. Next, an increased flock size was associated with a higher probability of that flock to be colonized with Campylobacter (Berndtson et al. 1996b, Barrios et al. 2006). Finally, in commercial flocks, the appearance of Campylobacter-specific bacteriophages and naturally occurring anti-Campylobacter substances have been associated with changes in level of colonization (Connerton et al. 2004, El-Shibiny et al. 2005), and cecal colonization of birds receiving plant-protein-based feed is significantly lower compared to that of birds receiving animal-protein-based feed or a combination of these two protein sources (Udayamputhoor et al. 2003).

\section{Sources for horizontal Campylobacter transmission to broiler flocks}

Colonized livestock and free-living animals are an important risk factor for transmitting C. jejuni to broiler flocks as C. jejuni genotypes from cattle, pigs, and laying hens, present at poultry farms, can also be found in the broiler flocks (van de Giessen et al. 1996, Ridley et al. 2008, Zweifel et al. 2008, EllisIversen et al. 2009, Allen et al. 2011). Bovine Campylobacter isolates are indeed able to efficiently colonize chickens (Hanel et al. 2009) and might thus be a source for broiler chicken infection and human disease, although they differ significantly from chicken and human isolates by a reduced prev- alence of two genetic markers especially, the $d m s A$ and $\gamma$-glutamate transpeptidase $(g g t)$ gene, important for persistent colonization of C. jejuni in chickens (Barnes et al. 2007, Gonzalez et al. 2009). Probably, only bovine clones carrying $g g t$ are able to efficiently colonize chicks and are thus a possible source for the transmission of $C$. jejuni to broiler flocks, but this hypothesis has yet to be confirmed. Whether $g g t$-negative C. jejuni clones are capable to acquire this marker through genetic exchange with ggt-positive clones, thereby promoting its successful colonization in the chicken gut, has yet to be examined. Also, several other studies revealed the presence of identical C. jejuni clones in bovines, chickens, and humans (Nielsen et al. 1997, On et al. 1998, Gilpin et al. 2008, Ragimbeau et al. 2008, Hakkinen et al. 2009, Huang et al. 2009), and even turkeys, sheep, water, dogs, and ostriches (Siemer et al. 2004). Recently, it was shown by molecular typing that Campylobacter strains from a broiler house and from an adjacent dairy farm were similar to those subsequently detected in the flock, indicating the importance of horizontal transmission and the risk of transmission of Campylobacter on multispecies farms (Ridley et al. 2011). This study also indicated that bovine fecal Campylobacter strains can colonize chickens, which was confirmed later on by Patriarchi et al. (2011). On a German farm, indistinguishable isolates of clonal origin were found in different flocks during the same rearing period (Ellerbroek et al. 2010). This suggests that Campylobacter strains might be transmitted from one broiler flock to another or might point toward a common external source infecting multiple broiler flocks at the same farm.

Also rodents, flies, and their larvae are potential vectors for C. jejuni transmission to broiler flocks (Berndtson et al. 1996a, Hald et al. 2004, 2008, Nichols 2005, Hazeleger et al. 2008). The importance of rodents as a potential vector is, however, somewhat controversial. Messens et al. (2009) stated that rodents should not be considered as a significant risk factor for the introduction of Campylobacter in broiler houses due to frequently applied on-farm rodent control programs. Meerburg (2010), on the other hand, stated that these programs are often poorly operated and mainly applied for economic, rather than for food safety purposes. Indeed, an association has been shown between the presence of rodents on farms and an increased risk for flocks to become infected with Campylobacter (McDowell et al. 2008), supporting Meerburg's hypothesis.

Another important source of infection is contaminated surface water as genotypes found in broilers can sometimes be detected in water puddles and ditch water as well, before the flocks are colonized (Bull et al. 2006, Messens et al. 2009). C. jejuni survival in water is promoted by several factors, including biofilm formation and possibly the viable but nonculturable state, in which C. jejuni enters when outside a suitable host (Sparks 2009). Biofilm formation has, however, been associated with decreased colonization potential in 1-day-old broiler chicks (Hanning et al. 2009). Viable but nonculturable $C$. jejuni cells are not believed to have reduced ability to attach to surfaces and once attached they may persist undetectable and be introduced into the food chain as soon as they come into contact with animals or products (Duffy and Dykes 2009).

Personnel and farm equipment such as trucks, forklifts, pallets, crates, and footwear have also been identified as potential sources of C. jejuni infection of broilers (Ramabu et al. 2004). Farm vehicles are often contaminated with 
Campylobacter even after cleaning (Ridley et al. 2011b). Also, broiler flocks on farms with three or more broiler houses, low frequency of footbath disinfectant change, and decreased cleanliness of the broiler house ante-room have an increased risk to become colonized (McDowell et al. 2008).

Finally, partial depopulation/thinning of broiler flocks (early removal of a part of the birds) has been implicated as a potential risk factor for Campylobacter colonization of the remainder of the animals of these flocks due to difficulties in maintaining biosecurity during thinning (Patriarchi et al. 2011). Allen et al. (2008) observed an association between C. jejuni genotypes present on vehicles and crates arriving on a farm at thinning, and those subsequently recovered from the birds after slaughter. In addition, during this process particular C. jejuni strains were able to spread from one farm to another (nearby farm) when sharing the same bird-catching personnel and/or vehicles. However, in several other studies, no increased risk associated with this process has been shown (Russa et al. 2005, Barrios et al. 2006, Näther et al. 2009).

\section{Transmission through the flock}

Once flock colonization is detected, bird-to-bird transmission within flocks is very rapid. A recent mathematical model revealed a transmission rate of 2.37 (van Gerwe et al. 2009) new cases per colonized chick per day. This implies that in a flock of 20,000 broilers, the prevalence of Campylobacter would increase from one infected bird to $95 \%$ within the week after the first bird is infected. Indeed, in a study by Stern et al. (2001), the majority $(95 \%-100 \%)$ of birds in a flock were colonized within 7 days after contact with a single (Campylobacter-colonized) seeder bird, regardless of the age of the animals. Drinking water and feed are believed to play an important role in the fecal-oral spread through the flock (Evans 1992, Gregory et al. 1997, Herman et al. 2003, Newell and Fearnley 2003, Sparks 2009). Once a flock is colonized, the nipple water is often contaminated with $C$. jejuni strains that are indistinguishable from those isolated from the broilers, indicating the importance of drinking water in transmitting this zoonotic pathogen throughout the flock (Gellynck et al. 2008, Messens et al. 2009).

\section{The effect of transportation}

Transport-induced stress has been shown to increase both the Campylobacter load (by $0.7 \log _{10} \mathrm{cfu} / \mathrm{g}$ ) in broiler ceca (Stern et al. 1995) as well as its excretion rates in broiler feces (by $0.8 \log _{10} \mathrm{cfu} / \mathrm{g}$ ) after transport (Whyte et al. 2001). Neither transportation distance nor duration significantly influenced the rate of Campylobacter shedding (Stern et al. 1995, Whyte et al. 2001). Transport crates are often still contaminated with Campylobacter when reused because crate decontamination processes are mostly ineffective (Ridley et al. 2011b). Contaminated crates can lead to external contamination of birds at partial thinning of the flock and during transport of a negative flock to the processing plant (Slader et al. 2002, Herman et al. 2003, Hansson et al. 2005, Rasschaert et al. 2007, Ridley et al. 2011b). However, there is still controversy about the possible role of transport crates in transmission of Campylobacter. Evidence for intestinal (co-)colonization due to transport in Campylobacter-contaminated containers was not found (Rasschaert et al. 2007). On the other hand, C. jejuni genotypes commonly associated with chickens were dominantly found on transport equipment and persisted throughout the decontamination process, indicating that improperly disinfected transport crates could be involved in Campylobacter contamination of poultry flocks (Hastings et al. 2010, Patriarchi et al. 2011).

\section{Carcass Contamination}

A significant correlation exists between the Campylobacter colonization rate of broiler chickens during rearing and bacterial counts on their carcasses after processing (Herman et al. 2003, Rasschaert et al. 2006, Rosenquist et al. 2006, Reich et al. 2008). Worldwide, an average prevalence of Campylobacter-contaminated poultry carcasses is reported to be in the range of $60 \%-80 \%$ (Suzuki and Yamamoto 2009, EFSA 2010c, Mullner et al. 2010). Similarly as in live animals of a poultry flock, also on poultry carcasses $C$. jejuni is the predominating species (Rasschaert et al. 2006, Kuana et al. 2008, Suzuki and Yamamoto 2009, EFSA 2010a, 2010c). Almost all parts of contaminated carcasses, whether fresh, chilled, or frozen, are frequently contaminated with Campylobacter and are all likely to be important sources for disease in humans (Berndtson et al. 1992). Carcass contamination occurs during defeathering and evisceration, by contaminated feces leaking from the cloaca and visceral rupture of ceca carrying a high Campylobacter load (Berrang et al. 2001).

The source of the majority of Campylobacter genotypes contaminating a flock during the slaughter process is probably the live flock (Herman et al. 2003, Rosenquist et al. 2003, Colles et al. 2010). Indeed, colonized broiler batches are far more likely to result in contaminated carcasses after processing compared to Campylobacter-free batches (EFSA 2010b). Moreover, Campylobacter isolates found in the ceca of broilers are very often similar to those isolated from the corresponding carcasses (Normand et al. 2008). There is, however, evidence that the slaughter process increases the diversity of Campylobacter genotypes isolated from a flock (Colles et al. 2010), suggesting that other sources are involved as well. Indeed, carcasses can also become contaminated by crosscontamination of Campylobacter between birds within a flock and between flocks slaughtered successively (Herman et al. 2003, Rosenquist et al. 2003, Rasschaert et al. 2006) and even between flocks slaughtered in the same area, as evidenced in Quebec by Normand et al. (2008). Campylobacter-colonized flocks contaminate the abattoir environment upon entering the room and as a consequence Campylobacter can be isolated at all stages of the processing line (Ellerbroek et al. 2010). C. jejuni is able to survive overnight on these processing equipment surfaces, even after cleaning and disinfection (Peyrat et al. 2008). Therefore, surviving strains might possibly be a source of poultry carcass contamination of subsequent flocks, probably by intestinal contents of previously processed Campylobacter-colonized flocks (Newell et al. 2001, Miwa et al. 2003).

\section{Combined hygienic approach to reduce Campylobacter prevalence in poultry}

It is clear that lots of risk factors are involved in the environmental transmission of Campylobacter to broiler flocks (Table 1). Possibly, these factors are intimately linked with each other. The increased temperature during summer months for instance could promote the presence of flies 
and rodents at the farm, whereas increased rain fall can create water puddle reservoirs in which C. jejuni can persistent and transmit to other vectors (Jorgensen et al. 2011). Therefore, source attribution for Campylobacter colonization in poultry flocks is not straightforward and only a combined approach of properly implemented hygienic measures in all of these areas will be capable to significantly reduce the number of Campylobacter colonized flocks. Indeed, intensive on-farm cleaning procedures in the UK did reduce Campylobacter prevalence on broiler-harvesting equipment, vehicles and personnel but failed to reduce Campylobacter colonization of broiler flocks (Ridley et al. 2011b). This combined approach must aim at minimizing the probability that Campylobacter enters the broiler room (by rodent and insect control, foodbath disinfection for personnel working in the broiler room, and drinking water treatment), reduce bird-to-bird transmission (drinking water treatment), and prevent cross-contamination during transport (by decontamination of transport crates) and slaughter. Together with measures taken at retail, as well as consumer information campaigns, such an approach led to a $74 \%$ decrease in human campylobacteriosis cases attributed to poultry in New Zealand in 2008, resulting in a 54\% decline in the overall notification rate for this country in 2008 compared to the 2002 to 2006 situation (Sears et al. 2011; see above). Because detailed data on Campylobacter prevalence in poultry flocks during this time course are not available, it can only be speculated that the decline in human illness in 2008 was due to a reduced prevalence of pathogenic C. jejuni in poultry that year.

\section{Transmission to Humans}

Transmission to humans most commonly occurs through consumption and handling of all kinds of foods of animal origin of which the carcasses are contaminated by Campylobacter during slaughter and carcass processing (Berrang et al. 2001, EFSA 2010c). In industrialized countries, handling, preparation, and consumption of contaminated chicken meat is considered to be the main source of infection in humans (Berndtson et al. 1992, Friedman et al. 2004). However, regular consumption of chicken meat reduces the risk for illness associated with recent chicken consumption, suggesting that partial immunity, conferring protection against Campylobacter, could be developed (Tam et al. 2009). By using genetic typing methods (see further) it was evidenced that chicken meat Campylobacter isolates can frequently be linked to human cases of campylobacteriosis. However, the overall genotypic diversity between isolates indicates that there are other sources contributing to disease in humans as well (de Haan et al. 2010, Thakur et al. 2010). Indeed, besides poultry, also nonpoultry farm animals can contribute to campylobacteriosis in humans. Not only does Campylobacter colonization of such animals pose a risk of contamination of their carcasses at slaughter, but it can also lead to the contamination of milk and surface water at the farm, as well as colonization of broiler flocks present at these farms (Doyle and Roman 1982, Stanley and Jones 2003, Garrett et al. 2006, Hannon et al. 2009), which are all risk factors for transmitting C. jejuni to humans. Also, direct contact with cattle, but also pets, in particular puppies with diarrhea, is a possible route of contamination (Tenkate and Stafford 2001, de Haan et al. 2010). Cattle and their direct environment are thus potential reservoirs for zoonotic C. jejuni strains (Kwan et al. 2008). Next, also drinking water has been implicated as a possible source for human illness, although in the developed world waterborne infection of Campylobacter in humans is not very likely (Young et al. 2007). Finally, also raw vegetables, which can become contaminated by cross-contamination by other contaminated food products during preparation, but also directly at the farm, are an important source (Gardner et al. 2011, Verhoeff-Bakkenes et al. 2011), and were suggested to be the second highest risk factor, after handling and consumption of contaminated chicken products (Evans et al. 2003).

\section{Contribution of the Chicken Reservoir to Campylobacteriosis in Humans}

Due to the wide-spread occurrence of Campylobacter spp. their environmental cycle is not very well understood. Moreover, due to the possibility of cross-contamination, tracing the genuine source of Campylobacter infections is not straightforward. By using a genetic approach, however, Wilson et al. (2008) estimated that $97 \%$ of the number of sporadic human campylobacteriosis cases in England is attributable to animals farmed for meat, with chicken and cattle as main sources for C. jejuni. Wild animal and environmental sources would only contribute for $3 \%$ of the cases. These results indicate that contaminated food products are the principle source for disease in humans. Stern and Kazmi (1989) stated already over two decades ago that a large number of C. jejuni serotypes from poultry can frequently be linked to human cases of campylobacteriosis. This was confirmed by later reports using also genetic typing techniques (Zorman et al. 2006, Gonzalez et al. 2009, Mullner et al. 2010). In 1997 in Denmark, $36 \%$ of broilers were colonized by C. jejuni and a large overlap of the most common serotypes in humans and broiler chickens was shown (Nielsen et al. 1997). Biotyping and pulsed-field gel electrophoresis analysis revealed that $\sim 20 \%$ of human Campylobacter isolates were genetically related to poultry isolates (Nadeau et al. 2002). Colles et al. (2008) found a significant similarity between chicken meat and human disease C. jejuni isolates. Comparison of Campylobacter fla-SVR genotypes isolated from humans and poultry revealed few significant differences in the distribution of genotypes over these two hosts (Wassenaar et al. 2009). Lindmark et al. (2009) detected a significant correlation between the presence of a particular C. jejuni subtype in patients and the consumption of fresh poultry meat during the same period and within the same geographical area. Together, all these observations indicate that certain C. jejuni strains circulate between poultry and humans, highlighting poultry as an important source for transmitting this pathogen to humans. This hypothesis is also strengthened by the observation that during the Belgian dioxin crisis in 1999, a withdrawal of chicken meat from the market in June coincided with a $40 \%$ decrease in human Campylobacter infections during that month (Vellinga and Van Loock 2002). Very recently, evidence of transmission by direct contact with poultry carcasses was given by Friis et al. (2010), who isolated identical strains from a poultry abattoir and a person that had developed campylobacteriosis upon entering that abattoir. Thus, there is increasing evidence that the broiler chick is a major reservoir for C. jejuni pathogenic to humans and that broiler chicken 
meat contaminated with this zoonotic pathogen is the most important source for disease. For the European situation it was estimated that Campylobacter-contaminated chicken meat would be responsible for up to $40 \%$ of human campylobacteriosis cases. The chicken reservoir as a whole might even be responsible for up to $80 \%$ of the cases, because strains from the chicken reservoir may reach humans by pathways other than food (EFSA 2010c). As a consequence, eradicating Campylobacter from poultry lines could tremendously reduce Campylobacter enteritis in humans. Unfortunately, no effective, reliable intervention measure is available to date to reduce Campylobacter colonization in poultry (Hermans et al. 2011a). Neither the overall prevalence of this pathogen in chicken retail products, nor the number of reported poultry meat consumption-related human campylobacteriosis cases were reduced in recent years (EFSA 2010c, EFSA and ECDC 2011).

\section{Concluding Remarks}

Campylobacter occurs wide-spread in the environment and several vectors are able to transmit this pathogen to humans. Additionally, cross-contamination of several of these sources can occur, making genuine source attribution of campylobacteriosis cases in humans not straightforward. However, increasing evidence is available that the chicken reservoir is the main vector for Campylobacter transmission to humans. Chickens are a natural host for zoonotic Campylobacter species and broilers carry high bacterial numbers in their ceca until slaughter. This eventually results in contamination of their carcass in the abattoir. Recent reports using genetic typing methods proved that the poultry vector is indeed capable of transmitting this pathogen to humans. Despite the increasing evidence that poultry is the number one contributor to disease in humans, no effective strategy exists to reduce the Campylobacter prevalence in broiler flocks. As a consequence, the incidence of campylobacteriosis in humans remains strikingly high. A better insight into the Campylobacter ecology and epidemiology in chicks must therefore help to identify the rearing stages where the zoonotic pathogen can be introduced or persist in a flock. By focussing on these critical points it could be possible to develop intervention measures that are capable to minimize the number of colonized flocks and contaminated carcasses, and thus the number of human campylobacteriosis cases associated with the chicken vector. In the mean time it is of utmost importance that hygienic measures are properly implemented at all stages during rearing, forming a combined approach to limit Campylobacter entrance into a flock.

\section{Acknowledgments}

In the authors' research groups, research on Campylobacter is financially supported by the Federal Public Service of Health, Food Chain Safety and Environment (FOD, Brussels, Belgium): project RT08/8-CAMPOUL.

\section{Author Disclosure Statement}

No competing financial interests exist.

\section{References}

Abulreesh, HH, Paget, TA, Goulder, R. Campylobacter in waterfowl and aquatic environments: incidence and methods of detection. Environ Sci Technol 2006; 40:7122-7131.
Ailes, E, Demma, L, Hurd, S, Hatch, J, et al. Continued decline in the incidence of Campylobacter infections, FoodNet 1996-2006. Foodborne Pathog Dis 2008; 5:329-337.

Allen, VM, Ridley, AM, Harris, JA, Newell, DG, et al. Influence of production system on the rate of onset of Campylobacter colonization in chicken flocks reared extensively in the United Kingdom. Br Poult Sci 2011; 52:30-39.

Allen, VM, Weaver, H, Ridley, AM, Harris, JA, et al. Sources and spread of thermophilic Campylobacter spp. during partial depopulation of broiler chicken flocks. J Food Prot 2008; 71: 264-270.

Baker, MG, Sneyd, E, Wilson, NA. Is the major increase in notified campylobacteriosis in New Zealand real? Epidemiol Infect 2007; 135:163-170.

Barnes, HA, Bagnall, MC, Browning, DD, Thompson, SA, et al. Gamma-glutamyl transpeptidase has a role in the persistent colonization of the avian gut by Campylobacter jejuni. Microb Pathog 2007; 43:198-207.

Barrios, PR, Reiersen, J, Lowman, R, Bisaillon, J-R, et al. Risk factors for Campylobacter spp. colonization in broiler flocks in Iceland. Prev Vet Med 2006; 74:264-278.

Beery, JT, Hugdahl, MB, Doyle, MP. Colonization of gastrointestinal tracts of chicks by Campylobacter jejuni. Appl Environ Microbiol 1988; 54:2365-2370.

Berndtson, E, Danielsson-Tham, ML, Engvall, A. Campylobacter incidence on a chicken farm and the spread of Campylobacter during the slaughter process. Int J Food Microbiol 1996a; 32:35-47.

Berndtson, E, Emanuelson, U, Danielsson-Tham, M-L. A 1-year epidemiological study of campylobacters in 18 Swedish chicken farms. Prev Vet Med 1996b; 26:167-185.

Berndtson, E, Tivemo, M, Engvall, A. Distribution and numbers of Campylobacter in newly slaughtered broiler chickens and hens. Int J Food Microbiol 1992; 15:45-50.

Berrang, ME, Buhr, RJ, Cason, JA, Dickens, JA. Broiler carcass contamination with Campylobacter from feces during defeathering. J Food Prot 2001; 64:2063-2066.

Bull, SA, Allen, VM, Domingue, G, Jørgenson, F, et al. Sources of Campylobacter spp. colonizing housed broiler flocks during rearing. Appl Environ Microbiol 2006; 72:645-652.

Cawthraw, S, Ayling, R, Nuijten, P, Wassenaar, T, et al. Isotype, specificity, and kinetics of systemic and mucosal antibodies to Campylobacter jejuni antigens, including flagellin, during experimental oral infections of chickens Sources of Campylobacter spp. colonizing housed broiler flocks during rearing. Avian Dis $1994 ; 38: 341-349$.

Colles, FM, Jones, TA, McCarthy, ND, Sheppard, SK, et al. Campylobacter infection of broiler chickens in a free-range environment. Environ Microbiol 2008; 10:2042-2050.

Colles, FM, McCarthy, ND, Sheppard, SK, Layton, R, et al. Comparison of Campylobacter populations isolated from a free-range broiler flock before and after slaughter. Int J Food Microbiol 2010; 137:259-264.

Connerton, PL, Loc Carrillo, CM, Swift, C, Dillon, E, et al. Longitudinal study of Campylobacter jejuni bacteriophages and their hosts from broiler chicken. Appl Environ Microbiol 2004; 70:3877-3883.

de Haan, CPA, Kivistö, RI, Hakkinen, M, Corander, J, et al. Multilocus sequence types of Finnish bovine Campylobacter jejuni isolates and their attribution to human infections. BMC Microbiol 2010; 10:200.

Doyle, MP, Roman, DJ. Prevalence and survival of Campylobacter jejuni in unpasteurized milk. Appl Environ Microbiol 1982; 44:1154-1158. 
Duffy, LL, Dykes, GA. The ability of Campylobacter jejuni cells to attach to Stainless steel does not change as they become nonculturable. Foodborne Pathog Dis 2009; 6:631-634.

European Food Safety Authority (EFSA). Analysis of the baseline survey on the prevalence of Campylobacter in broiler batches and of Campylobacter and Salmonella on broiler carcasses in the EU, 2008, Part A: Campylobacter and Salmonella prevalence estimates. EFSA J 2010a; 8:1503.

EFSA. Analysis of the baseline survey on the prevalence of Campylobacter in broiler batches and of Campylobacter and Salmonella on broiler carcasses, in the EU, 2008, Part B: Analysis of factors associated with Campylobacter colonisation of broiler batches and with Campylobacter contamination of broiler carcasses, and investigation of the culture method diagnostic characteristics used to analyse broiler carcass samples. EFSA J 2010b; 8:1522.

EFSA and ECDC. The European Union summary report on trends and sources of zoonoses, zoonotic agents and foodborne outbreaks in 2009. EFSA J 2011; 9:2090.

EFSA. Panel on Biological Hazards (BIOHAZ). Scientific opinion on quantification of the risk posed by broiler meat to human campylobacteriosis in the EU. EFSA J 2010c; 8:1437.

Ellerbroek, LI, Lienau, J-A, Klein, G. Campylobacter spp. in broiler flocks at farm level and the potential for crosscontamination during slaughter. Zoonoses Public Health 2010; 57:e81-e88.

Ellis-Iversen, J, Jorgensen, F, Bull, S, Powell, L, et al. Risk factors for Campylobacter colonisation during rearing of broiler flocks in Great Britain. Prev Vet Med 2009; 89:178-184.

El-Shibiny, A, Connerton, PL, Connerton, IF. Enumeration and diversity of Campylobacters and bacteriophages isolated during the rearing cycles of free-range and organic chickens. Appl Environ Microbiol 2005; 71:1259-1266.

Evans, MR, Ribeiro, CD, Salmon, RL. Hazards of healthy living: bottled water and salad vegetables as risk factors for Campylobacter infection. Emerg Infect Dis 2003; 9:12191225.

Evans, SJ. Introduction and spread of thermophilic campylobacters in broiler flocks. Vet Rec 1992; 131:574-576.

Evans, SJ, Sayers, AR. A longitudinal study of campylobacter infection of broiler flocks in Great Britain. Prev Vet Med 2000; 46:209-223.

Friedman, CR, Hoekstra, RM, Samuel, M, Marcus, R, et al. Risk factors for sporadic Campylobacter infection in the United States: a case-control study in FoodNet sites. Clin Infect Dis 2004; 38:S285-S296.

Friis, C, Wassenaar, TM, Javed, MA, Snipen, L, et al. Genomic characterization of Campylobacter jejuni strain M1. PLoS ONE 2010; 58:e12253.

Gardner, TJ, Fitzgerald, T, Xavier, C, Klein, R, et al. Outbreak of campylobacteriosis associated with consumption of raw peas. Clin Infect Dis 2011; 53:26-32.

Garrett, N, Devane, ML, Hudson, JA, Nicol, C, et al. Statistical comparison of Campylobacter jejuni subtypes from human cases and environmental sources. J Appl Microbiol 2007; 103:2113-2121.

Gellynck, X, Messens, W, Halet, D, Grijspeerdt, K, et al. Economics of reducing Campylobacter at different levels within the Belgian poultry meat. J Food Prot 2008; 71:479-485.

Gilpin, BJ, Thorrold, B, Scholes, P, Longhurst, RD, et al. Comparison of Campylobacter jejuni genotypes from dairy cattle and human sources from the Matamata-Piako District of New Zealand. J Appl Microbiol 2008; 105:1354-1360.

Gonzalez, M, Hakkinen, M, Rautelin, H, Hanninen, ML. Bovine Campylobacter jejuni strains differ from human and chicken strains in an analysis of certain molecular genetic markers. Appl Environ Microbiol 2009; 75:1208-1210.

Gregory, E, Barnhart, H, Dreesen, DW, Stern, NJ, et al. Epidemiological study of Campylobacter spp. in broilers: source, time of colonization, and prevalence. Avian Dis 1997; 41:890-898.

Hakkinen, M, Nakari, UM, Siitonen, A. Chickens and cattle as sources of sporadic domestically acquired Campylobacter jejuni infections in Finland. Appl Environ Microbiol 2009; 75:52445249.

Hald, B, Skovgard, H, Bang, DD, Pedersen, K, et al. Flies and Campylobacter infection of broiler flocks. Emerg Infect Dis 2004; 10:1490-1492.

Hald, B, Skovgard, H, Pedersen, K, Bunkenborg, H. Influxed insects as vectors for Campylobacter jejuni and Campylobacter coli in Danish broiler houses. Poult Sci 2008; 87:1428-1434.

Hanel, I, Borrmann, E, Muller, J, Muller, W, et al. Genomic and phenotypic changes of Campylobacter jejuni strains after passage of the chicken gut. Vet Microbiol 2009; 136:121-129.

Hanning, I, Donoghue, DJ, Jarquin, R, Kumar, GS, et al. Campylobacter biofilm phenotype exhibits reduced colonization potential in young chickens and altered in vitro virulence. Poult Sci 2009; 88:1102-1107.

Hannon, SJ, Taboada, EN, Russell, ML, Allan, B, et al. Genomicsbased molecular epidemiology of Campylobacter jejuni isolates from feedlot cattle and from people in Alberta, Canada. J Clin Microbiol 2009; 47:410-420.

Hansson, I, Ederoth, M, Andersson, L, Vagsholm, I, et al. Transmission of Campylobacter spp. to chickens during transport to slaughter. J Appl Microbiol 2005; 99:1149-1157.

Hastings, R, Colles, FM, McCarthy, ND, Maiden, MCJ, et al. Campylobacter genotypes from poultry transportation crates indicate a source of contamination and transmission. J Appl Microbiol 2010; 110:266-276.

Hazeleger, WC, Bolder, NM, Beumer, RR, Jacobs-Reitsma, WF. Darkling beetles (Alphitobius diaperinus) and their larvae as potential vectors for the transfer of Campylobacter jejuni and Salmonella enterica Serovar Paratyphi B variant Java between successive broiler flocks. Appl Environ Microbiol 2008; 74:6887-6891.

Herman, L, Heyndrickx, M, Grijspeerdt, K, Vandekerchove, D, et al. Routes for Campylobacter contamination of poultry meat: epidemiological study from hatchery to slaughterhouse. Epidemiol Infect 2003; 131:1169-1180.

Hermans, D, Van Deun, K, Messens, W, Martel, A, et al. Campylobacter control in poultry by current intervention measures ineffective: urgent need for intensified fundamental research. Vet Microbiol 2011a; 52:219-228.

Hermans, D, Pasmans, F, Heyndrickx, M, Van Immerseel, F, et al. A tolerogenic mucosal immune response leads to persistent Campylobacter jejuni colonization in the chicken gut. Crit Rev Microbiol 2011b; doi:10.3109/1040841X.2011.615298.

Huang, JL, Xu, HY, Bao, GY, Zhou, XH, et al. Epidemiological surveillance of Campylobacter jejuni in chicken, dairy cattle and diarrhoea patients. Epidemiol Infect 2009; 137:11111120.

Jacobs-Reitsma, WF, van de Giessen, AW, Bolder, NM, Mulder, RW. Epidemiology of Campylobacter spp. at two Dutch broiler farms. Epidemiol Infect 1995; 114:413-421.

Jerome, JP, Bell, JA, Plovanich-Jones, AE, Barrick, JE, et al. Standing genetic variation in contingency loci drives the rapid adaptation of Campylobacter jejuni to a novel host. PLoS ONE 2011; 6:e16399.

Jokinen, C, Edge, TA, Ho, S, Koning, W, et al. Molecular subtypes of Campylobacter spp., Salmonella enterica, and 
Escherichia coli $\mathrm{O} 157: \mathrm{H7}$ isolated from faecal and surface water samples in the Oldman River watershed, Alberta, Canada. Water Res 2011; 45:1247-1257.

Jonsson, ME, Heier, BT, Norström, M, Hofshagen, M. Analysis of simultaneous space-time clusters of Campylobacter spp. in humans and in broiler flocks using a multiple dataset approach. Int J Health Geogr 2010; 9:48.

Jorgensen, F, Ellis-Iversen, J, Rushton, S, Bull, SA, et al. Influence of season and geography on Campylobacter jejuni and C. coli subtypes in housed broiler flocks reared in Great Britain. Appl Environ Microbiol 2011; 77:3741-3748.

Kuana, SL, Santos, LR, Rodrigues, LB, Borsoi, A, et al. Occurrence and characterization of Campylobacter in the Brazilian production and processing of broilers. Avian Dis 2008; 52:680-684.

Kudirkiene, E, Malakauskas, M, Malakauskas, A, Bojesen, AM, et al. Demonstration of persistent strains of Campylobacter jejuni within broiler farms over a 1-year period in Lithuania. I Appl Microbiol 2010; 108:868-877.

Kwan, PSL, Barrigas, M, Bolton, FJ, French, NP, et al. Molecular epidemiology of Campylobacter jejuni populations in dairy cattle, wildlife, and the environment in a farmland area. Appl Environ Microbiol 2008; 74:5130-5138.

Lindmark, H, Boqvist, S, Ljungström, M, Ågren, P, et al. Risk factors for campylobacteriosis: an epidemiological surveillance study of patients and retail poultry. J Clin Microbiol 2009; 47:2616-2619.

McDowell, SWJ, Menzies, FD, McBride, SH, Oza, A, et al. Campylobacter spp. in conventional broiler flocks in Northern Ireland: epidemiology and risk factors. Prev Vet Med 2008; 84:261-276.

Meade, KG, Nirciandi, F, Cahalane, S, Reiman, C, et al. Comparative in vivo infection models yield insights on early host immune response to Campylobacter in chickens. Immunogenetics 2009; 61:101-110.

Meerburg, BG. Rodents are a risk factor for the spreading of pathogens on farms. Vet Microbiol 2010; 142:464-465.

Meldrum, RJ, Griffiths, JK, Smith, RMM, Evans, MR. The seasonality of human Campylobacter infection and Campylobacter isolates from fresh, retail chicken in Wales. Epidemiol Infect 2005; 133:49-52.

Messens, W, Herman, L, De Zutter, L, Heyndrickx, M. Multiple typing for the epidemiological study of contamination of broilers with thermotolerant Campylobacter. Vet Microbiol 2009; 138:120-131.

Miwa, N, Takegahara, Y, Terai, K, Kato, H, et al. Campylobacter jejuni contamination on broiler carcasses of $C$. jejuni-negative flocks during processing in a Japanese slaughterhouse. Int J Food Microbiol 2003; 84:105-109.

Mullner, P, Collins-Emerson, JM, Midwinter, AC, Carter, P, et al. Molecular epidemiology of Campylobacter jejuni in a geographically isolated country with a uniquely structured poultry industry. Appl Environ Microbiol 2010; 76:2145-2154.

Murphy, C, Carroll, C, Jordan, KN. Environmental survival mechanisms of the foodborne pathogen Campylobacter jejuni. J Appl Microbiol 2006; 100:623-632.

Nadeau, E, Messier, S, Quessy, S. Prevalence and comparison of genetic profiles of Campylobacter strains isolated from poultry and sporadic cases of campylobacteriosis in humans. J Food Prot 2002; 65:73-78.

Näther, G, Alter, T, Martin, A, Ellerbroek, L. Analysis of risk factors for Campylobacter species infection in broiler flocks. Poult Sci 2009; 88:1299-1305.

Newell, DG. The ecology of Campylobacter jejuni in avian and human hosts and in the environment. Int J Infect Dis 2002; 6:3S16-3S21.
Newell, DG, Fearnley, C. Sources of Campylobacter colonization in broiler chickens. Appl Environ Microbiol 2003; 69:4343-4351. Newell, DG, Shreeve, JE, Toszeghy, M, Domingue, G, et al. Changes in the carriage of Campylobacter strains by poultry carcasses during processing in abattoirs. Appl Environ Microbiol 2001; 67:2636-2640.

Nichols, GL. Fly transmission of Campylobacter. Emerg Infect Dis 2005; 11:361-364.

Nielsen, EM, Engberg, J, Madsen, M. Distribution of serotypes of Campylobacter jejuni and C. coli from Danish patients, poultry, cattle and swine. FEMS Immunol Med Microbiol 1997; 19: $47-56$.

Normand, V, Boulianne, M, Quessy, S. Evidence of crosscontamination by Campylobacter spp. of broiler carcasses using genetic characterization of isolates. Can J Vet Res 2008; 72: 396-402.

Ogden, ID, Dallas, JF, MacRae, M, Rotariu, O, et al. Campylobacter excreted into the environment by animal sources: prevalence, concentration shed, and host association. Foodborne Pathog Dis 2009; 6:1161-1170.

On, SL, Nielsen, EM, Engberg, J, Madsen, M. Validity of SmaIdefined genotypes of Campylobacter jejuni examined by SalI, KpnI, and BamHI polymorphisms: evidence of identical clones infecting humans, poultry, and cattle. Epidemiol Infect 1998; 120:231-237.

Patriarchi, A, Fox, A, Maunsell, B, Fanning, S, et al. Molecular characterization and environmental mapping of Campylobacter isolates in a subset of intensive poultry flocks in Ireland. Foodborne Pathog Dis 2011; 8:99-108.

Petersen, L, Wedderkopp, A. Evidence that certain clones of Campylobacter jejuni persist during successive broiler flock rotations. Appl Environ Microbiol 2001; 67:2739-2745.

Peyrat, MB, Soumet, C, Maris, P, Sanders, P. Recovery of Campylobacter jejuni from surfaces of poultry slaughterhouses after cleaning and disinfection procedures: analysis of a potential source of carcass contamination. Int J Food Microbiol 2008; 124:188-194.

Ragimbeau, C, Schneider, F, Losch, S, Even, J, et al. Multilocus sequence typing, pulsed-field gel electrophoresis, and fla short variable region typing of clonal complexes of Campylobacter jejuni strains of human, bovine, and poultry origins in Luxembourg. Appl Environ Microbiol 2008; 74:7715-7722.

Ramabu, SS, Boxall, NS, Madie, P, Fenwick, SG. Some potential sources for transmission of Campylobacter jejuni to broiler chickens. Lett Appl Microbiol 2004; 39:252-256.

Rasschaert, G, Houf, K, Van Hende, J, De Zutter, L. Campylobacter contamination during poultry slaughter in Belgium. J Food Prot 2006; 69:27-33.

Rasschaert, G, Houf, K, Van Hende, J, De Zutter, L. Investigation of the concurrent colonization with Campylobacter and Salmonella in poultry flocks and assessment of the sampling site for status determination at slaughter. Vet Microbiol 2007; 123:104-109.

Reich, F, Atanassova, V, Haunhorst, E, Klein, G. The effects of Campylobacter numbers in caeca on the contamination of broiler carcasses with Campylobacter. Int J Food Microbiol 2008; 127:116-120.

Ridley, AM, Allen, VM, Sharma, M, Harris, JA, et al. Real-time PCR approach for detection of environmental sources of Campylobacter strains colonizing broiler flocks. Appl Environ Microbiol 2008; 74:2492-2504.

Ridley, AM, Morris, VK, Cawthraw, SA, Ellis-Iversen, JE, et al. Longitudinal molecular epidemiological study of thermophilic Campylobacters on one conventional broiler chicken farm. Appl Environ Microbiol 2011a; 77:98-107. 
Ridley, A, Morris, V, Gittins, J, Cawthraw, S, et al. Potential sources of Campylobacter infection on chicken farms: contamination and control of broiler-harvesting equipment, vehicles and personnel. J Appl Microbiol 2011b; 111:233-244.

Rosenquist, H, Nielsen, NL, Sommer, HM, Norrung, B, et al. Quantitative risk assessment of human campylobacteriosis associated with thermophilic Campylobacter species in chickens. Int J Food Microbiol 2003; 83:87-103.

Rosenquist, H, Sommer, HM, Nielsen, NL, Christensen, BB. The effect of slaughter operations on the contamination of chicken carcasses with thermotolerant Campylobacter. Int J Food Microbiol 2006; 108:226-232.

Russa, AD, Bouma, A, Vernooij, JCM, Jacobs-Reitsma, W, et al. No association between partial depopulation and Campylobacter spp. colonization of Dutch broiler flocks. Lett Appl Microbiol 2005; 41:280-285.

Sahin, O, Luo, N, Huang, S, Zhang, Q. Effect of Campylobacterspecific maternal antibodies on Campylobacter jejuni colonization in young chickens. Appl Environ Microbiol 2003; 69:5372-5379.

Siemer, BL, Harrington, CS, Nielsen, EM, Borck, B, et al. Genetic relatedness among Campylobacter jejuni serotyped isolates of diverse origin as determined by numerical analysis of amplified fragment length polymorphism (AFLP) profiles. J Appl Microbiol 2004; 96:795-802.

Slader, J, Domingue, G, Jorgensen, F, McAlpine, K, et al. Impact of transport crate reuse and of catching and processing on Campylobacter and Salmonella contamination of broiler chickens. Appl Environ Microbiol 2002; 68:713-719.

Sparks, NHC. The role of the water supply system in the infection and control of Campylobacter in chicken. Worlds Poult Sci J 2009; 65:459-473.

Stanley, K, Jones, K. Cattle and sheep farms as reservoirs of Campylobacter. J Appl Microbiol 2003; 94:104S-113S.

Stas, T, Jordan, FTW, Woldehiwet, Z. Experimental infection of chickens with Campylobacter jejuni: strains differ in their capacity to colonize the intestine. Avian Pathol 1999; 28:61-64.

Stern, NJ. Salmonella species and Campylobacter jejuni cecal colonization model in broilers. Poult Sci 2008; 87:2399-2403.

Stern, NJ, Clavero, MRS, Bailey, JS, Cox, NA, et al. Campylobacter spp. in broilers on the farm and after transport. Poult Sci 1995; 74:937-941.

Stern, NJ, Cox, NA, Musgrove, MT, Park, CM. Incidence and levels of Campylobacter in broilers after exposure to an inoculated seeder bird. J Appl Poult Res 2001; 10:315-318.

Stern, NJ, Kazmi, SU. Campylobacter jejuni. In: Doyle, MP, ed. Food-Borne Bacterial Pathogens. New York: Marcel Dekker Inc., 1989:71-110.

Suzuki, H, Yamamoto, S. Campylobacter contamination in retail poultry meats and by-products in Japan: a literature survey. Food Control 2009; 20:531-537.

Tam, CC, Higgins, CD, Neal, KR, Rodrigues, LC, et al. Chicken consumption and use of acid-suppressing medications as risk factors for Campylobacter enteritis, England. Emerg Infect Dis 2009; 15:1402-1408.

Tenkate, TD, Stafford, RJ. Risk factors for Campylobacter infection in infants and young children: a matched case-control study. Epidemiol Infect 2001; 127:399-404.

Thakur, S, Zhao, S, McDermott, PF, Harbottle, H, et al. Antimicrobial resistance, virulence, and genotypic profile comparison of Campylobacter jejuni and Campylobacter coli isolates from humans and retail meats. Foodborne Pathog Dis 2010; 7:835-844.

Udayamputhoor, RS, Hariharan, H, Van Lunen, TA, Lewis, PJ, et al. Effects of diet formulations containing proteins from different sources on intestinal colonization by Campylobacter jejuni in broiler chickens. Can J Vet Res 2003; 67:204-212.

Uzunović-Kamberović, S, Zorman, T, Heyndrickx, M, Smole Možina, S. Role of poultry meat in sporadic Campylobacter infections in Bosnia and Herzegovina: laboratory-based study. Croat Med J 2007; 48:842-851.

van de Giessen, A, Mazurier, SI, Jacobs-Reitsma, W, Jansen, W, et al. Study on the epidemiology and control of Campylobacter jejuni in poultry broiler flocks. Appl Environ Microbiol 1992; 58:1913-1917.

van de Giessen, AW, Bloemberg, BP, Ritmeester, WS, Tilburg, JJ. Epidemiological study on risk factors and risk reducing measures for Campylobacter infections in Dutch broiler flocks. Epidemiol Infect 1996; 117:245-250.

van Gerwe, T, Miflin, JK, Templeton, JM, Bouma, A, et al. Quantifying transmission of Campylobacter jejuni in commercial broiler flocks. Appl Environ Microbiol 2009; 75:625-628.

Vellinga, A, Van Loock, F. The dioxin crisis as experiment to determine poultry-related Campylobacter enteritis. Emerg Infect Dis 2002; 8:19-22.

Verhoeff-Bakkenes, L, Jansen, HAPM, in't Veld, PH, Beumer, RR. Consumption of raw vegetables and fruits: a risk factor for Campylobacter infections. Int J Food Microbiol 2011; 144: 406-412.

Wassenaar, TM, Fernandez-Astorga, A, Alonso, R, Marteinsson, VT, et al. Comparison of Campylobacter fla-SVR genotypes isolated from humans and poultry in three European regions. Lett Appl Microbiol 2009; 49:388-395.

Wedderkopp, A, Nielsen, EM, Pedersen, K. Distribution of Campylobacter jejuni Penner serotypes in broiler flocks 19982000 in a small Danish community with special reference to serotype 4-complex. Epidemiol Infect 2003; 131:915-921.

Whyte, P, Collins, JD, McGill, K, Monahan, C, et al. The effect of transportation stress on excretion rates of Campylobacters in market-age broilers. Poult Sci 2001; 80:817-820.

Whyte, P, McGill, K, Cowley, D, Madden, RH, et al. Occurrence of Campylobacter in retail foods in Ireland. Int J Food Microbiol 2004; 95:111-118.

Wilson, DJ, Gabriel, E, Leatherbarrow, AJH, Cheesbrough, J, et al. Tracing the source of campylobacteriosis. PLoS Genet 2008; 4:e1000203.

Young, KT, Davis, LM, Dirita, VJ. Campylobacter jejuni: molecular biology and pathogenesis. Nat Rev Microbiol 2007; 5:665-679.

Zorman, T, Heyndrickx, M, Uzunović-Kamberović, S, SmoleMožina, S. Genotyping of Campylobacter coli and C jejuni from retail poultry meat and humans with campylobacteriosis in Slovenia and Bosnia and Herzegovina. Int J Food Microbiol 2006; 110:24-33.

Zweifel, C, Scheu, KD, Keel, M, Renggli, F, et al. Occurrence and genotypes of Campylobacter in broiler flocks, other farm animals, and the environment during several rearing periods on selected poultry farms. Int J Food Microbiol 2008; 125: 182-187.

Address correspondence to: David Hermans

Department of Pathology, Bacteriology and Avian Diseases Faculty of Veterinary Medicine Ghent University Salisburylaan 133 Merelbeke 9820 Belgium

E-mail: david.hermans@ugent.be 
This article has been cited by:

1. A.S. Obeng, H. Rickard, M. Sexton, Y. Pang, H. Peng, M. Barton. 2012. Antimicrobial susceptibilities and resistance genes in Campylobacter strains isolated from poultry and pigs in Australia. Journal of Applied Microbiology 113:2, 294-307. [CrossRef] 